\title{
Sociomoral Reasoning in Children With Respect to Exclusion and Inclusion Relationships*
}

\author{
Jaime Yáñez-Canal \\ Universidad Nacional de \\ Colombia, Bogotá, \\ Colombia
}

\author{
Elfriede \\ Billmann-Mahecha \\ Leibniz University of \\ Hanover, Hannover, \\ Germany
}

\author{
Yohana Andrea Mójica \\ Mójica \\ Universidad Santo Tomás \\ de Aquino, Bogotá, \\ Colombia
}

\author{
Adriana Perdomo \\ Pontificia Universidad \\ Javeriana, Bogotá, \\ Colombia
}

\begin{abstract}
The goal of this study is the analysis of judgments by children and adolescents with regard to inclusion and exclusion in its moral, personal, and social senses. Interviews were conducted with 96 Colombian children and adolescents of diverse social origins and of different age groups (5, 9, 13, and 17 years old). The interviews focused on three types of situations in which peers were excluded from group activities. The qualitative analyses show that children and adolescents gradually gain complexity in their descriptions of situations, and their judgments become more flexible, differentiated, and integrated. Different models of moral development are discussed, and in conclusion we propose that moral development can be best understood as a process of increasing complexity and of differentiation-integration of domains.
\end{abstract}

Keywords: moral development, sociomoral reasoning, moral judgment

\section{Introduction}

There are some innovative theories in current philosophy and moral psychology that define moral judgment and moral action in a way that differs from the Kantian-Piagetian tradition. These theories are found among the communitarians (Kymlicka, 1990; MacIntyre, 2007; Sandel, 1982; Taylor, 1989; Walzer, 1983), pragmatists (Rorty, 1994), and post-Kohlbergians (Turiel, 1983, 1998; Turiel, Killen, \& Helwig, 1987; Turiel \& Smetana, 1989; Varela, 1996). They attempt to capture the diversity of human knowledge processes and the processes of signification that occur therein.

Cognitive proposals in philosophy and psychology conceive moral judgment as a formal process that all subjects follow in order to operate in diverse situations. Kant, Rawls, Hare, Piaget, and Kohlberg proposed a universal way of judging and reasoning about moral problems, that allowed the individual to impartially

\footnotetext{
*Acknowledgements: This research was supported by Colciencias (code 1101-10-13875) and the División de investigaciones de la Universidad Nacional de Colombia, sede Bogotá (DIB). We thank Jairo Gómez for his help on methodology. We also thank Carlos Kölbl, Clara Arboleda, Maria Elvia Domínguez and Víctor Cervante for their help and critical comments. Finally, we thank Amparo Forero, who participated in the first part of this study, and we thank the management and students of the following schools for their invaluable support: Colegio Santo Ángel de la Guarda, Liceo de Cervantes-Norte, C.E.D El Japón and C.E.D Prado-Anfes.

Jaime Yáñez-Canal, Ph.D., associate professor, Universidad Nacional de Colombia.

Elfriede Billmann-Mahecha, Ph.D., professor, Leibniz University of Hanover.

Yohana Andrea Mójica Mójica, Master, Universidad Santo Tomás de Aquino.

Adriana Perdomo, Master, Pontificia Universidad Javeriana.
} 
analyze an infinity of situations and contemplate all the elements relevant in a moral conflict in an even-handed way. Kohlberg (1984) posited that the most developed moral thinking is that in which the subject is able to differentiate moral reasons from personal and social reasons in his own judgments. The moral, according to Kohlberg (1984), is made possible in human reasoning when the subject disregards all personal bonds, customs and cultural and social demands. The individual and social realms are understood by Kohlberg as being in tight relation to interests and specific bonds that impede the consideration of the whole of humanity, and the establishment of equality among all human beings. Piaget and Kohlberg consider that human development must be understood as a process that leads to more abstraction, autonomy, and liberation from the immediate and particular. The concrete, usually understood as a part of primitive thought, is linked to the affective, to personal interests and relations, to the variable, the egocentric, and the pre-moral. The abstract, often defined through certain logical models or formal processes, is, on the contrary, associated with the possibility of systematization, with the universal, with principles, and with moral thought.

Unlike Kohlberg and the Piagetian tradition, some authors (Dreyfus, 1993a, 1993b; Turiel, 1983, 1998; Varela, 1996; Yáñez, 2000) consider that development follows a path towards concretization and expertise. The end result is that the individual is able to recognize the different demands of different contexts, and to perform analyses with ever more precise elements, more rich in variability and flexibility. In this process of gaining expertise, human beings must develop different domains of knowledge that depend on the particular demands of certain contexts. These domains of knowledge operate in different ways; no one domain must be understood as a part or component of another more widely encompassing form; no one domain is associated with a more primitive form of knowledge or judgment.

This perspective considers the social and the personal as two domains with their own characteristics. These domains are distinct from the moral domain which, although complimentary to the two domains mentioned above, has an independent development (Nucci, 2001; Turiel, 1983, 1998; Turie et al., 1987; Turiel \& Smetana, 1989). These domains follow independent routes of development because they refer to different aspects of human interaction. The social and the personal domains must be differentiated from the moral with regard to the aspects that each domain encompasses and the types of judgment that each domain produces. Whereas the domain of the personal is referred to the ways in which subjects recognize spaces of individual decision, the social is referred to the functioning of social institutions and the norms that regulate human interaction. The domain of the moral, on the other hand, is the domain, which expresses concern for the well-being of others, or the discourse directed towards achieving equality and dignity for all human beings. Obviously, there are situations in which a mixture of domains presents itself. Some examples are the recognition of moral obligations in friendships, the recognition of the right of people to choose their friendships and spaces of intimate encounters, and the creation of institutional rules to guarantee equality and individual development.

Initial research on domain differentiation shows that children consider physical damage (hitting or shoving others), psychological damage (nicknames, mocking, or hurting other's feelings), and impartiality or justice (giving to each what each deserves, equal opportunity) to be actions in the moral domain. Furthermore, children and adolescents judge that moral problems are obligatory, not contingent upon the existence of rules or consensuses, and that those problems cannot be solved through the dictates of an authority and cannot be validated by common practice in a group or culture (Brown, 1989; Killen \& Stangor, 2001; Turiel, 1983, 1998; Stangor \& Ruble, 1989; Stoddart \& Turiel, 1985). The domain of social knowledge is aimed towards a greater 
specific knowledge and demands a capacity for contextual understanding and a greater flexibility to recognize norms and social rules.

Theoretical antecedents of the conceptualization of the personal domain are found in the works of Erikson (1963) and Stern (1985), for example. These works point out that since the time children learn to walk, they also begin to discover a level of autonomy and a space of personal decisions. Children claim recognition of a certain space of autonomous decision from adults at a very early age. The earliest age at which subjects can differentiate domains is two and a half. Smetana and Braeges (1990) showed that subjects at that age were more willing to generalize moral issues to other contexts, like considering it wrong to hit another child without provocation, than to generalize social norms. These authors believe that three-year-olds are already capable of differentiating moral and social judgments by applying rules of gravity, contingency, and generalizability. Many studies corroborate these findings. Studies developed in northern Brazil, the Virginia Islands as well as studies developed with Christian and Muslim children in Indonesia, Jewish children in Israel, children and adults in India, Korea, Nigeria, and Zambia all show the same processes of differentiation between the moral and the social domains (Smetana, 1995).

According to Killen and Stangor (2001), even though studies on exclusion of peers and on the behavioral parameters of group exclusion are abundant, they have not contemplated how children analyze exclusion with the particular characteristics of groups and their specific demands as a starting point. It is clear that, according to certain characteristics of associations, or according to the activities to be carried out, groups usually have to establish criteria of admission or exclusion in order, for example, to accomplish a given goal or plan. In other words, the act of "exclusion" does not necessarily have a moral connotation, in the sense that Turiel gives to this word. There are "social" situations that demand a member selection process that need not be perceived as incorrect or an attack on any right or duty.

The concept of "exclusion" may be considered as a kind of "bordering" concept since it may generate arguments and justifications of a moral kind, but may also be interpreted within what we have defined as social and personal judgment. Therefore, in an attempt to clearly separate the components of moral, personal, and social judgments, we will propose in our study a differentiation of groups in terms of the goals they want to attain. Informal groups seek only amusement and the bonding of their members. Groups constituted to carry out a task or seek a goal demand specific skills and have explicit selection criteria. The bonds and relations of friendship that join together a group of people are put in play in intimate situations. It should be pointed out that in the three kinds of groups just mentioned, there can be either moral or non-moral forms of exclusion, although reasons of personal or social kind to justify the exclusion may also be presented. In any case, reasons for exclusion given in each kind of group are closely linked to the nature and characteristics of the situations and of the sociomoral reasoning domains that each situation implies.

\section{Research Question and Hypothesis}

We attempt to comprehend how development in each domain of sociomoral judgment comes about, and how domains relate to each other in different stages of development. Although Turiel's theory constitutes the main conceptual framework for this study, we believe that the author's model of development has some limitations with regards to domain characterization and description, because of an insufficient attention to personal aspect and because of a poor characterization of relationships between domains. We attempt to overcome these limitations by more clearly focusing on the particularities between domains and their 
relationships.

Our hypothesis is that development consists in a process of domain differentiation and a process of growing flexibility in order to analyze the demands and characteristics of specific situations. Human beings in their sociomoral development achieve a progressive differentiation of domains, and with it, a richer and more complex relation among them, as well as an increase in presuppositions to interpret the variations in different contexts of human interaction.

The general objective of our investigation is the analysis of judgments by children and adolescents with regard to inclusion and exclusion in its moral, personal, and social sense. The specific objectives are: (1) to determine the differences in childhood development with regard to the capacity to differentiate and coordinate the moral, social, and personal domains; and (2) to identify the development of moral, social, and personal argumentations to justify or reject behaviors of exclusion.

\section{Method}

\section{Subjects}

This study was carried out with 96 children and adolescents (48 girls, 48 boys) attending four learning institutions (two private schools and two public schools) in Bogotá. The two public schools were co-ed, of secular orientation and with a population belonging to low economic strata (levels 1, 2, and 3). The two private schools were not co-ed, one was an all-boys school, the other all girls; both schools offer religious education and have students from high economic strata (4, 5, and 6). Four age ranges were specified for data recollection: 5, 9, 13, and 17 years of age. We decided to use these age groups because they constitute good levels in development that permit observation of a clearly defined and organized qualitative structure of reasoning.

\section{Interview Situation and Procedure}

Three situations were chosen which were different in the rules they may have for their implementation and the objectives sought therein, as well as in the demands that they posited to participants. The situations were presented to the subjects in the form of three different images (see Appendix A) which can be described as follows:

(1) Informal play image (children playing with a ball): This image shows a drawing of four informally dressed children playing in a disorderly manner with a ball, and one child that is isolated from the group. The objective of the activity is amusement and therefore any person could and should have the right to participate in it, regardless of what relations people have between them or the athletic abilities they may have;

(2) Volleyball image: This image displays a formal game of volleyball (with teams of two players on each side, each team with a distinctive uniform, in a clearly competitive situation), and two children that are not participating, informally dressed and watching the game. The main demand of this activity would be athletic skills and prowess; it also presupposes a series of obligatory rules and a restricted number of participants;

(3) Piñata image: This image shows a group of children playing around a piñata at a children's party, and two children watching from the outside through a window (their clothing shows a difference in terms of social class). This image was chosen because it suggests, in more developed subjects, the claim for the individual right to pick friendships and to establish, through consensus, the objectives of a gathering, as well as the possible rules 
of interaction in this context.

With the images presented as a starting point, a semi-structured interview was conducted on the investigation subjects, seeking to explore their reasons for explaining or justifying situations of inclusion-exclusion in groups. The following questions served as a guide: What is going on with the children that are apart? Why are these children not playing, why are they not with the others? When is it ok to exclude a child from the game? If only one more child could join the game, which of the two would you choose, and why? Why would you reject the other one? What would you do if you were in that situation? Which child would you pick? What would you do if you wanted or thought that someone should be allowed in the game but your best friend wanted to join the game instead, and asked you to let him, because of your friendship? What would you do if you picked one child and the other became sad because you did not let him join? Do you think it is right or correct to exclude someone from an activity? Do you think it is ok if you decide to exclude somebody (in the different situations)?

Groups of three participants each were organized according to age and gender, and they were each evaluated in two sessions with one week's time in between. In the first session the first two images were presented, in the second session the third one was presented. In both sessions first, individual interviews were conducted about each picture, then, the group was assembled to produce a discussion among the members.

\section{Qualitative Data Analysis}

For the sake of brevity, in this paper we only present the qualitative data analyses which are essential for understanding our research strategy. The main interest of the qualitative analysis was to clarify how sociomoral domains work, how they are manifested in children's argumentations, and how the process of development presents itself with respect to their judgments and the differentiation and integration of domains. With this orientation, following the analytic induction procedure (Taylor \& Bogdan, 1998), an initial interpretation on domains and the levels of development was formulated, and then was put under validation by expert judges. This interpretation became a point of reference in our advance in terms of categorization and analysis. This process resulted in the construction of specific categories and conglomerates of categories to codify the answers of inclusion and exclusion, differentiated previously as evaluation judgments (when the child analyzes the image), judgments of choice (when he/she explains what he/she would do if he/she were in a similar situation to that presented in the image) and of valuation (when he/she judges whether any decision taken to exclude or include somebody is good or correct).

\section{Results}

\section{Description of Domains}

A series of specific categories that arose from the interviews with children that constitute possible reasons to justify the problem of exclusion or inclusion were proposed as a result of our investigation. Each of these categories is related to one of the three domains of sociomoral judgment (moral, social-conventional, and personal-relational). The group was made up of 33 specific categories, which were later grouped in more encompassing categories that we called as conglomerates. Table 1 shows the association between domains, conglomerates, and specific categories. The characterization of domains present in our investigation was the following. The detailed description of the conglomerates and the specific categories linked to each domain is shown in Appendix B. 
Table 1

Association Between Domains, Conglomerates, and Specific Categories

\begin{tabular}{|c|c|c|}
\hline Judgment domain & Conglomerate & Specific category \\
\hline \multirow{12}{*}{ Moral domain } & \multirow{3}{*}{ Concern about harm } & Physical aggression \\
\hline & & Humiliation \\
\hline & & Revenge \\
\hline & \multirow{2}{*}{ Justice A } & Human rights \\
\hline & & Right to intimacy \\
\hline & \multirow{2}{*}{ Justice B } & Equal opportunity \\
\hline & & Egalitarianism \\
\hline & Ideal self A & I must be good \\
\hline & Ideal self B & I must be consistent with my principles \\
\hline & \multirow{3}{*}{ Benevolence } & Welfare \\
\hline & & Concern for the other \\
\hline & & The strongest \\
\hline \multirow{15}{*}{ Social-conventional domain } & \multirow{5}{*}{ Prejudice } & Gender \\
\hline & & Race \\
\hline & & Social class \\
\hline & & Political or religious beliefs, sexual orientation \\
\hline & & Other prejudices or stereotypes \\
\hline & \multirow{3}{*}{ Goals of the activity } & Skills for the activity \\
\hline & & Rules \\
\hline & & Goals of the activity \\
\hline & \multirow{5}{*}{ Social convention } & Non-compliance with norms \\
\hline & & Expected norms of good conduct \\
\hline & & Social convention \\
\hline & & Group characteristics \\
\hline & & Consensus \\
\hline & \multirow{2}{*}{ Fear of disapproval } & Particular authority \\
\hline & & Fear of sanctions \\
\hline \multirow{6}{*}{ Personal-relational domain } & \multirow{6}{*}{ Personal choice or preference } & Physical characteristics \\
\hline & & Personality traits \\
\hline & & Generated feelings \\
\hline & & Friendship \\
\hline & & Does not wish to participate in the activity \\
\hline & & Personal preference \\
\hline
\end{tabular}

Moral domain. According to Turiel, the moral domain encompasses the notions of justice, dignity, rights and equality, notions that are not determined by agreement or consensus but rather possess an intrinsic character of universality. This domain is also associated with the concern to prevent both physical and psychological harm and to guarantee the welfare of all persons. However, based on the data acquired in our investigation, we believe that it is important to include other aspects that Turiel did not contemplate in this domain. One of these aspects is the "Ideal self", which constitutes a powerful source of motivation for moral action, in that it is rooted in the subject's identity. This ideal encompasses a supposition on various types of action that people must perform and various feelings they must feel if they want to preserve their sense of self-consistency. Another aspect we included in this domain refers to a wide sense of benevolence, that goes 
beyond the simple consideration of welfare in terms of preventing harm to an individual or group and that includes the consideration of feelings, needs, or the particularities of the situation in which a certain subject or group is involved.

Social-conventional domain. This domain refers to social systems, social organization and conventions. It includes a consideration of norms, regularities and cultural or social practices whose meanings are defined by the system in which they are immersed. In this domain we also broaden the definition of what can be considered social-conventional with respect to Turiel. We include references to prejudices and stereotypes because this kind of ideas plays an important role in children's explanations of social functioning. Also, we include the consideration of the objectives of an activity or the motives for associating of a group. In this sense, we include in this domain the reference to the skills that a person is required to have to be accepted in a given group or activity.

Personal-relational domain. With Turiel's theory as a starting point, we believe that the personal-relational domain references non-moral actions that are not part of conventionally regulated systems. They are therefore judged to be part of the domain of personal choice. Said choice, in western cultures, includes the choice of friends, actions upon one's own body, and private correspondence and recreational activities. Nevertheless, we found it necessary in our research to broaden the definition of this domain to include the conception that a child has of what it means to be a person (a self or another) and the understanding of relations between persons and the changes in the concepts of these relations. Within this domain we may consider references not only to personal choices but also to personality characteristics of subjects, the kind of bond they establish and the intentions and motivations (including unconscious ones) that may determine the explanation of children about the human behavior.

\section{Stages of Sociomoral Development}

Once the definition of domains was accomplished, our analysis turned to the different ways in which the domains are manifested and the relations that are established among them. We also investigated the ways in which children express their arguments in relation to the kind of judgment that is demanded of them (evaluation, choice, or valuation), and in relation to the context. As a summary, we present the characterization of the stages of development stemming from our analysis of the performed interviews.

Stage 1 (five years of age). Personal-relational domain. Children in this stage have not yet achieved a full differentiation of their selves and others, that mean, children see themselves as physically but not psychologically differentiated from others. The child has still problems to put him/herself in someone else's place and understand his/her motives, feelings, or intentions. The only intentions that the child attributes to others to explain their behavior are those referred or associated to certain moral dispositions, for example, they say someone is envious, prone to fight, prone to dialogue and to sharing. General traits, when expressed, appear in order to rate someone in evaluative terms, independently of the situation in which the person evaluated is in. This limited capacity for contemplating psychological components impedes friendship from being understood as an interpersonal relationship built upon feelings, affinities and shared histories, and identities. Bonds are not a determining factor at this stage, and do not play any role in children's argumentation with respect to the validity of exclusion in different contexts.

Social-conventional domain. This stage presents inconsistent allusions that do not have to do with the rules of an activity or with roles, objectives, and goals. Children of this age do not differentiate contexts in 
terms of the particular characteristics of each activity or of each kind of group. Children's characterizations only contain evident descriptive elements or a few allusions to their own experiences or to everyday life. The child recognizes certain norms about elemental and independent actions, such as not using hands to grab the ball, taking turns to play, scoring goals etc.. The child does not take into account that the rules of the game are established in order to guarantee equal conditions for all, but rather sees them as a series of obligatory prescriptions of actions that are part of a set of varied activities. Not knowing how to play is not related with skills or abilities for a specific game; it is just a way of describing actions that give rise to rejection or that impede the satisfaction of an interest. Social norms foreign to the activity are included, and have a moral component that may lead to justifying excluding someone from the game or his/her receiving a drastic sanction. Examples of these social conducts are being late to the party, not being properly dressed, being dirty, swearing, dropping one's pants, lying, or not obeying the teacher.

Moral domain. Children of this age mainly give judgments of benevolence, or of prevention of harm to others. The child expresses his/her concern for possible damage that may be caused to him/her or others, although obviously this damage is associated to physical actions or to very evident negative feelings. These judgments are expressed to justify both exclusion and inclusion of the person in a game or activity. It is a special characteristic of five-year-olds that their judgments may vary, without stability, from rejection of the person who causes damage, to acceptance of the same person when he/she is perceived as also weak and with feelings of sadness or suffering. These ideas on the prevention of harm may reflect the first seeds of the idea of justice, because the child seeks to balance out differences between persons and establish conditions where there is no big difference of strength or opportunities among the people participating in the activity. In addition, 5-year-olds display a kind of egalitarianism geared towards giving everyone the same quantitative possibilities regardless of individual capacities or needs, or of the demands of the situation.

The ways in which the different domains manifest themselves for 5-year-olds lead the child to have a discourse about them that has little differentiation and integration. The children have difficulty in understanding the conventional nature of certain social norms, that they understand as obligatory in a strict moral manner and that they confuse the moral with the socio-conventional domain. The child may accept or recommend exclusion (and sometimes sanctions) for someone who is not liked by others, who is late to a party, who does not obey the teacher, who does not let others play, who does not want to play with others, who pays no attention to a given object, or who is inappropriately dressed for the occasion. At this age, we do not notice a difference between judgments of evaluation, choice, and valuation, except that evaluative judgments may condemn the possible negative conduct of the excluded and accept exclusion, whereas other sorts of judgments normally recommend the inclusion of all people.

Stage 2 (nine years of age). Personal-relational domain. It is important to point out the appearance, at this stage, of psychological justifications to explain the behaviors and facial expressions of the characters in the images. A differentiation of the self from others on the psychological plane also begins to emerge. Persons are described as being a certain way; although this description is understood in relation to recurring behaviors, not in relation to their intentions or personality traits. Bonds are characterized as an interpersonal relation that is constant in time; but there is no understanding of deep psychological characteristics such as a shared history or identity.

Social-conventional domain. Children of this age recognize certain rules and goals of games or of social gatherings, but this does not permit them to differentiate situations in terms of the demands made of 
participants or of the goals that may be therein pursued. Therefore, although they recognize that certain situations demand skills or knowledge to warrant participation; or that it is important that someone be an acquaintance in order to be admitted at a social gathering; or that winning is the goal of certain activities, these considerations are discarded when children judge the moral adequacy of excluding someone from an activity.

Moral domain. At this age, we also find judgments of benevolence, justice and the reestablishment of equality. Like the younger children, nine-year-olds are especially concerned about physical harm, as well as harm the feelings of the others. Unlike the younger children, however, they contemplate psychological aspects, both to describe harm-causing behaviors and to understand the hurt feelings that are thereby produced. In general, children at this stage say that everyone should be able to participate in an activity, as long as they desire to do so. Children of this age always seek solutions that allow everyone to play, even if the solution is unrelated to the game's conditions or to the situation in terms of competition. Therefore, it is usual to find in these children's judgments reasons to choose or favor the poorest, youngest, or weakest without regard to the rules of the game, the wishes of their parents or of their own friends. They choose those who are at a disadvantage as an attempt to integrate them in an activity or to give them certain benefits as a form of compensation.

This benevolent and justice-seeking concern of the child determines the relations he/she establishes among domains. Although the child is presently capable of differentiating the personal-relational, social-conventional and moral domains, he/she cannot produce an integrated discourse about them. This poor differentiation of domains can be explained by the elemental characterization that the child has of them, but also because of his concern to establish a strong sense of self based on a particular moral ideal.

Stage 3 (13 years of age). Personal-relational domain. Children of this age refer to the actors or participants in the situation using abstract categories (personality, character type) that account for a psychological make up with some stability. At this stage, psychological characterization is a deciding factor in children's argumentation and their acceptance or rejection of exclusion. A clear capacity for contemplating the perspective of the other, his/her circumstances, feelings, and thoughts is observed, when 13-year-olds take decisions and evaluate a situation. There is an understanding of reciprocity in interpersonal relations, which presupposes an understanding that the perspective of the others has consequences upon one's own, and vice-versa. This understanding is fundamental, in that it allows the child to contemplate multiple perspectives and seek an agreement through consensus that takes in account the interests of all the parties involved when presenting alternative solutions to the situation. Relatedly, the importance of the bond and the type of interpersonal relationships that are established is strengthened, and they become a determining factor in the child's reasoning. Friendship is understood in terms of a bond built upon affinities, shared history, common identifying references, and the support that a friend provides in different situations. The importance given to friendship and group decisions stands in contrast with the importance that 13-year-olds give to personal decisions and responsibility. People are made responsible for their behaviors and particular situations; in some cases, they are even made responsible for their disadvantaged situation, both economical and affective.

Social-conventional domain. Children of this age produce a differentiated discourse for each situation but are unable to order or give reasons in favor of a hierarchy of domains according to the demands or meanings of each context. They can spontaneously identify the objectives and the characteristics of each image, but, when asked to take a decision or evaluate the situation, personal bonds become the criterion to consider 
inclusion/exclusion, at the expense of the characteristics of the situation.

Moral domain. The 13-year-olds' appraisal of the self is not established in relation to certain acts that are seen as moral norms ("one must share with others", "one must talk to those one disagrees with”, like younger children said), but is rather established upon certain virtues that contemplate a person's motives or intentions. Likewise, because they can evaluate intentional qualities and because they can recognize certain stable attributes in others, their judgments of justice and benevolence are more clearly constituted. References to the rights of others appear at this age, understood as either equality of opportunities or equal consideration of others.

This concern for justice and benevolence can create certain conflicts with other domains; although these are already differentiated, they are not made part of an integrated discourse that establishes when and under what conditions one domain must prevail over another. When a conflict between different types of sociomoral reasons appears, children usually unload the responsibility of the inclusion/exclusion in others and/or the group. They propose new procedures and strategies to smooth out the possible consequences of a certain decision, and oscillate between one solution and another when probed with questions, without analyzing or elucidating the reasons for conflict.

Stage 4 (17 years of age). Personal-relational domain. Youths at this age display a rather complex understanding of other's psychological characteristics. They are capable of contemplating intentions, motivations, feelings, beliefs, and thoughts in other's acts and decisions. They can even present explanations about other's personalities, and unconscious motivations. This complex theory about other's psychological traits permits them to consider their peers as stable and organized psychological entities. Likewise, they recognize the stability and commitment of a relation of friendship, without implying absolute unconditionality, nor inflexibility in reclaiming certain obligations and rules.

Social-conventional domain. The youth can clearly differentiate the goals of activities and the rules called for in each situation, and can also contemplate more factors to take into account when analyzing each context. The youth spontaneously established a differentiation among kinds of games according to their different goals and different requisites for admission. This capacity to differentiate contexts, explain their particular characteristics, and establish why certain criteria or domains should or should not be taken into account when analyzing a given situation is equally evident with regards to social gatherings. The differentiation of different kinds of social gatherings leads subjects this stage to demand respect for certain rights that are associated with each context.

Moral domain. In accordance with context differentiation, where youths can identify different objectives, demands for skills or levels of acquaintance among participants as admission criteria, we can also find certain moral evaluations. Although the moral justification is different and relative to the characteristics of each context, subjects recognize that discrimination and the rejection of people based on race, creed, or social stratum is something that must be morally rejected; although many of their judgments are influenced by prejudice and stereotypes.

The most important achievement of this stage is the construction of a discourse where the relations between domains, and the way each domain should be taken into account in order to analyze different situations and to evaluate the adequacy of an exclusion behavior, are reflected. Because the subject can distinguish which criteria apply or correspond to each situation, he/she no longer displays the conflicts typical of the previous stage. Not only does he/she not display the former conflict among domains, but also 
the subject is now capable of explaining why these situations cannot produce conflicts among domains, and how these should be part of a flexible hierarchy that must be established according to the particularities of each situation.

\section{Discussion}

The psychology of moral development has usually understood judgment as a process structure of the whole that allows subjects to think in a coherent way when faced with myriad situations. Likewise, it has been supposed that in order to avoid moral relativism there must be some stable forms of judgment that allow for a clear evaluation of subjects' decisions and actions. The theories of Kohlberg (1984) and many others, in spite of their differences, proposed models to understand judgment in the way we explained above. But there are many theories in philosophy and psychology that question this way of understanding knowledge, judgment, and development. In certain theories human knowledge is understood as embedded in narratives or in the tacit agreements of a particular tradition that determines what is to be valued and how must one proceed in order to obtain results that are acceptable to all. This realm of implicit understanding establishes certain unknowable limits on the way problems can be understood and tackled. What elements and meanings are relevant for the analysis of a situation, what possibilities participants in a conflict have of resolving it, and which kinds of solutions ought to be positively or negatively evaluated, is something that remains to be determined.

However, recognizing that human knowledge and its judgment processes operate on a non-traceable horizon of meaning does not mean that any judgment goes and that we are defending a relativistic position. The reference to the concept of community, tradition, or narrative histories is proposed in order to establish the difficulties in accounting for negotiation processes or enthroning a particular form of human action as "the Universal” or "objective", or "moral”, or "rational” form of human action. The horizon of meaning, as well as the concept of community or the sense of belonging cannot be established with geographic or temporal limits, or with ideological benchmarks or conceptual icons that have as a pretension the revealing of creation mechanisms or the constitution of universes of meaning. The fact that there is currently a concern for justice, for certain forms of government, for certain ways of insuring an equal treatment of all human beings is due to the history of certain tradition, not to the maturity of human reason or the discovery of certain formal procedures. Likewise, the broadening of the concept of a peer or equal, the concern about universal forms of justice, the development of equal rights for minorities or the demand for respect, and equal consideration for the unborn is not the product of a development of "formal" structures, but a broadening of the presuppositions used to evaluate ethical situations.

Individual development is not a process of acquiring a greater capacity for impartiality or a gradual distancing from social meanings and presuppositions. Rather is to be understood as a gradual incorporation of the meanings and values of a given tradition. We, somewhat ironically, propose that development is a movement toward the concrete. The process of concretization is not proposed in order to insist in one of the poles of a dualistic perspective, but to stress the greater contextual flexibility of subjects that have achieved greater development. The concrete does not refer to a primitive intuition or to affects previous to and determining of reason, nor to an imaginative capacity that rebels against the designs of reason; it refers to a sense of adequacy that is permanently actualized in every act of interpretation. The more experienced subject, the one with a greater sense of belonging and contextual adequacy, can interpret the demands and meanings of 
ever changing contexts.

In the field of the psychology of moral development, this discussion has been presented in Turiel's writings on sociomoral domains and in the works of Dreyfus (1993a; 1993b) and Varela (1996). Dreyfus and Varela hold that moral judgment cannot be established in terms of clearly established cognitive processes and that the development of knowledge processes follow a path towards ever richer and more precise concretization and differentiation of contexts and social meanings. Turiel (1983; 1998), although with different theoretical concerns, offered heuristic possibilities for understanding the process of concretization and differentiation of contexts. Sociomoral domain theory proposes a separation of contexts according to the demands and meanings of each one, allowing the understanding of all the complexity and variability of subject's moral judgments.

Our research proposes new information to understand the moral development as a process of concretization or expertise. Thus, we would like to point out two aspects that are worth for the larger debate on the psychology of moral development: the characterization of domains and the view of moral development as a process of differentiation-integration. In our study, we find that developing subjects gradually gain complexity in their descriptions of situations, and their judgments become more flexible, differentiated, and integrated. The older adolescents were more capable of understanding the psychological characteristics of others, and more able to accept the dynamics of a friendship, or of social functioning. Likewise, they could more easily understand social norms and the conventional demands of each context, as well as differentiate obligations from commitments. Finally, as for the moral domain, subjects could gradually understand which demands could be put in the categories of rights and duties and how responsibilities depend on contexts and particular situational demands.

Parallel to this process of increasing judgment complexity, subjects displayed an ever greater capacity to differentiate and integrate different domains. Young children, although lacking an adequate understanding of the moral, social-conventional and personal relational domains, judged in a strict manner on the conditions and responsibilities in all the contexts that we analyzed, and expressed their judgments in a moralizing way. More developed subjects, on the contrary, were able to recognize the demands of each situation and could establish discourses on the strength or role that each domain had in each situation, as well as of differentiating the rules and characteristics of each domain or context and to establish varied relations among domains according to the particularities of each context.

\section{References}

Brown, B. (1989). The role of peer groups in adolescent's adjustment to secondary school. In T. Bemdt, \& G. Ladd (Eds.), Peer relationships in child development (pp. 188-215). Wiley: New York.

Dreyfus, H. L. (1993a). Was ist moralische reife? Eine phänomenologische Darstellung der Entwicklung ethischer Expertise (What is moral maturity? A phenomenological exposition of the development of ethical expertise). Deutsche Zeitschrift fiir Philosophie, 41, 435-458.

Dreyfus, H. L. (1993b). Was computer noch immer nicht können (What computers still cannot do). Deutsche Zeitschrift für Philosophie, 41, 653-680.

Erikson, E. H. (1963). Childhood and society. Norton: New York.

Killen, M., \& Stangor, C. (2001). Children's social reasoning about inclusion and exclusion in gender and race peer group contexts. Child Development, 72, 174-186.

Kohlberg, L. (1984). Essays on moral development, Vol. II: The psychology of moral development: The nature and validity of moral stages. San Francisco, C.A.: Harper \& Row.

Kymlicka, W. (1990). Contemporary political philosophy. Oxford: Clarendon Press.

MacIntyre, A. (2007). After virtue: A study in moral theory (3rd ed.). Notre Dame, I.N.: University of Notre Dame Press. 
Nucci, L. (2001). Education in the moral domain. Cambridge, M.A.: Cambridge University Press.

Rorty, R. (1994). Hoffnung statt Erkenntnis. Eine Einfiihrung in die pragmatische Philosophie (Hope in place of knowledge: An introduction to pragmatism). Wien: Passagen Verlag.

Sandel, M. J. (1982). Liberalism and the limits of justice. Cambridge, M.A.: Cambridge University Press.

Smetana, J. G. (1995). Morality in context: Abstractions, ambiguities, and applications. Annals of Child Development, 10, 83-130.

Smetana, J. G., \& Braeges, J. L. (1990). The development of toddler's moral and conventional judgments. Journal of Developmental Psychology, 36(3), 329-346.

Stangor, C., \& Ruble, D. N. (1989). Differential influences of gender schemata and gender constancy on children's information processing behavior. Social Cognition, 7, 353-372.

Stoddart, T., \& Turiel, E. (1985). Children’s concepts of cross-gender activities. Child Development, 56, 1241-1252.

Stern, D. (1985). The interpersonal world of the infant: A view from psychoanalysis and developmental psychology. New York: Basic Books.

Taylor, C. (1989). Sources of the self: The making of the modern identity. Harvard: Harvard University Press.

Taylor, S. J., \& Bogdan, R. (1998). Introduction to qualitative research methods (3rd ed.). New York: Wiley.

Turiel, E. (1983). The development of social knowledge: Morality and convention. Cambridge: Cambridge University Press.

Turiel, E. (1998). The development of morality. In N. Eisenberg (Ed.), Handbook of child psychology: Vol. 3: Social, emotional, and personality development (pp. 863-932). New York: Wiley.

Turiel, E., Killen, M., \& Helwig, C. C. (1987). Morality: Its structure, functions, and vagaries. In J. Kagan, \& S. Lamb (Eds.), The emergence of morality in young children (pp. 155-244). Chicago: University of Chicago Press.

Turiel, E., \& Smetana, M. (1989). Conocimiento social y acción: La coordinación de los dominios. In E. Turiel, \& M. Smetana (Eds.), El mundo social en la mente infantil (pp. 389-408). Madrid: Ed. Alianza.

Varela, F. (1996). Ética y acción. Santiago de Chile: Dolmen Ediciones.

Walzer, M. (1983). Spheres of justice. Oxford: Blackwell.

Yáñez-Canal, J. (2000). Debates en la psicología del desarrollo moral. In Diálogos (pp. 117-143). Bogotá: Universidad Nacional de Colombia.

Yáñez-Canal, J. (2001). El debate Kohlberg-Gilligan, algo más que un problema de género. In A. Robledo, \& Y. Puyana (Eds.), Ética, masculinidades y feminidades (pp. 273-354). Bogotá: Universidad Nacional de Colombia.

Appendix A: The Images

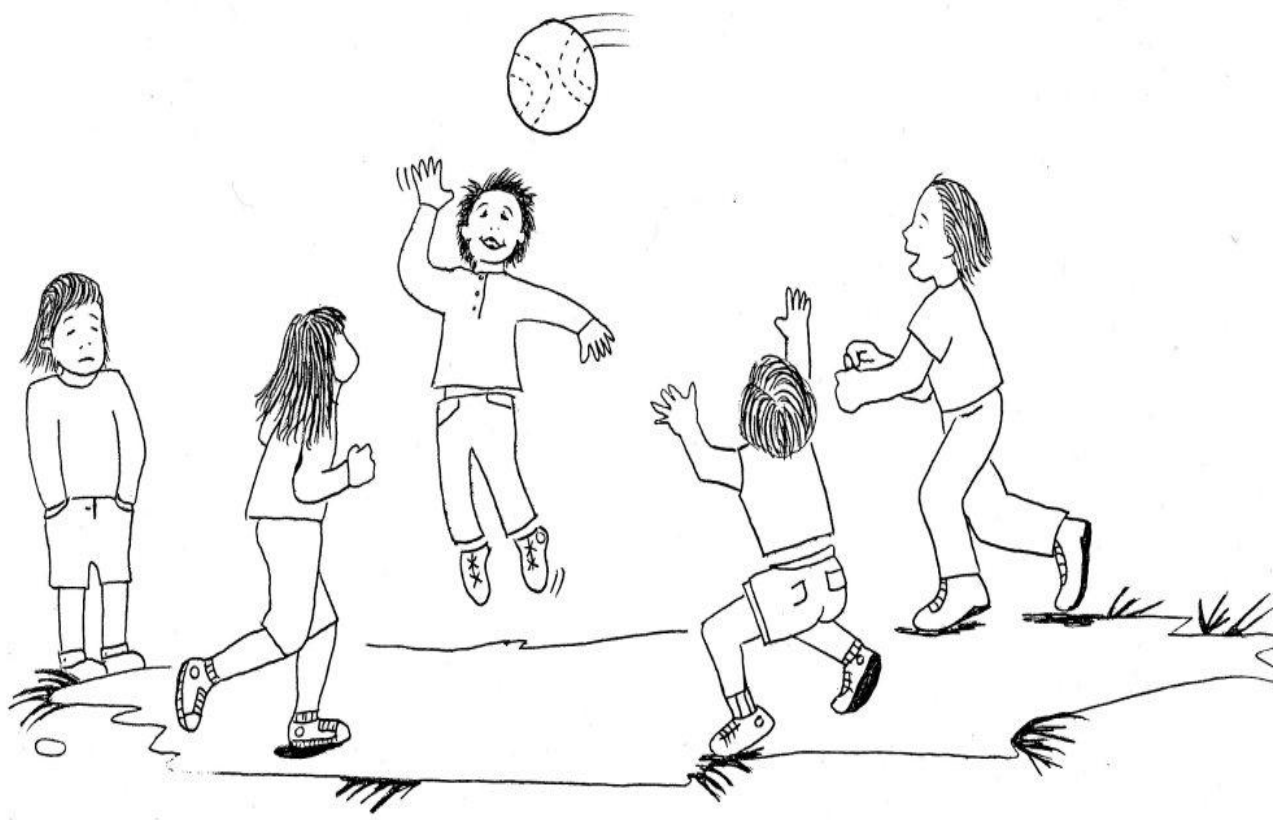

Figure A1. Informal play image. 


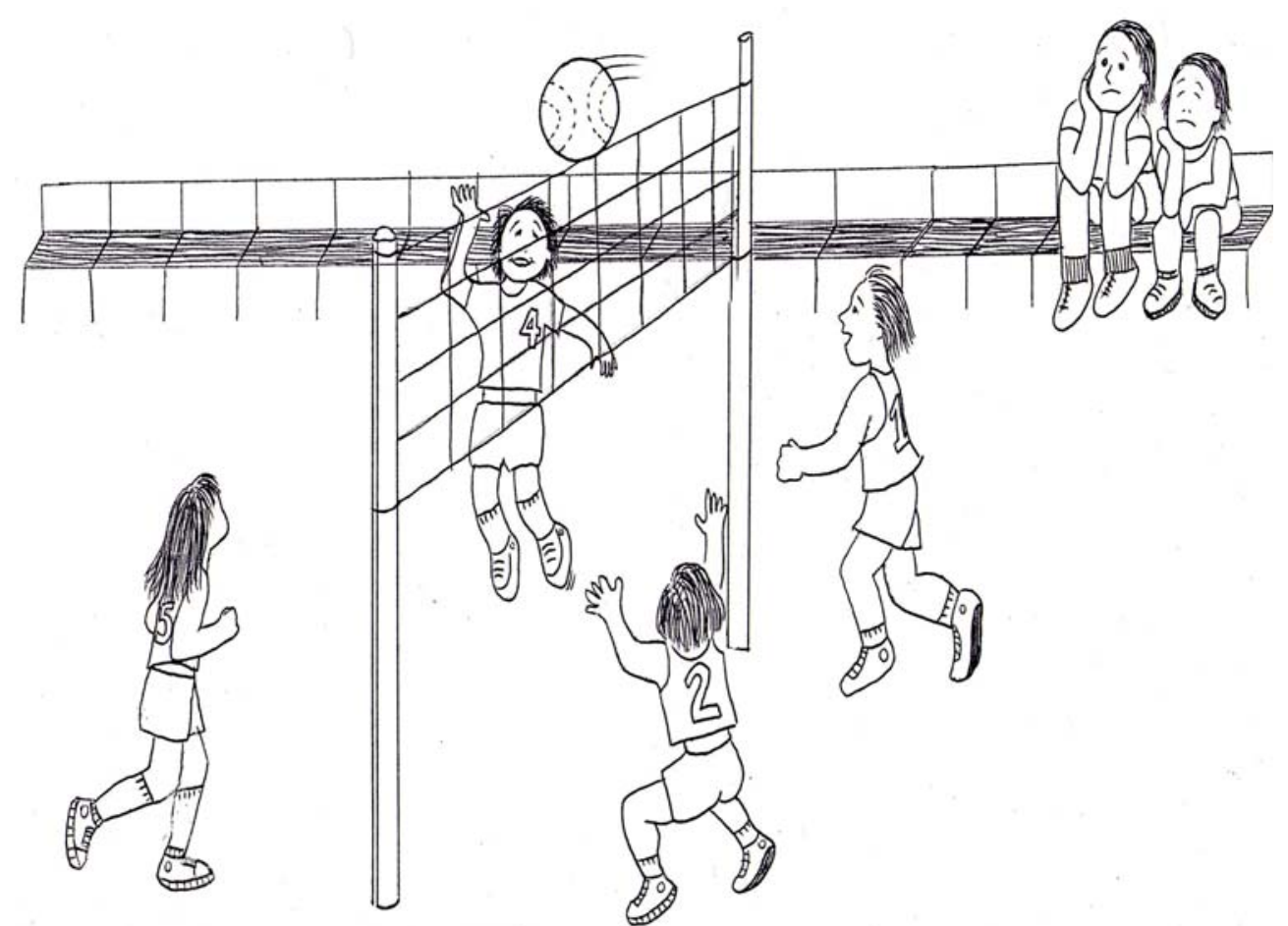

Figure A2. Volleyball image.

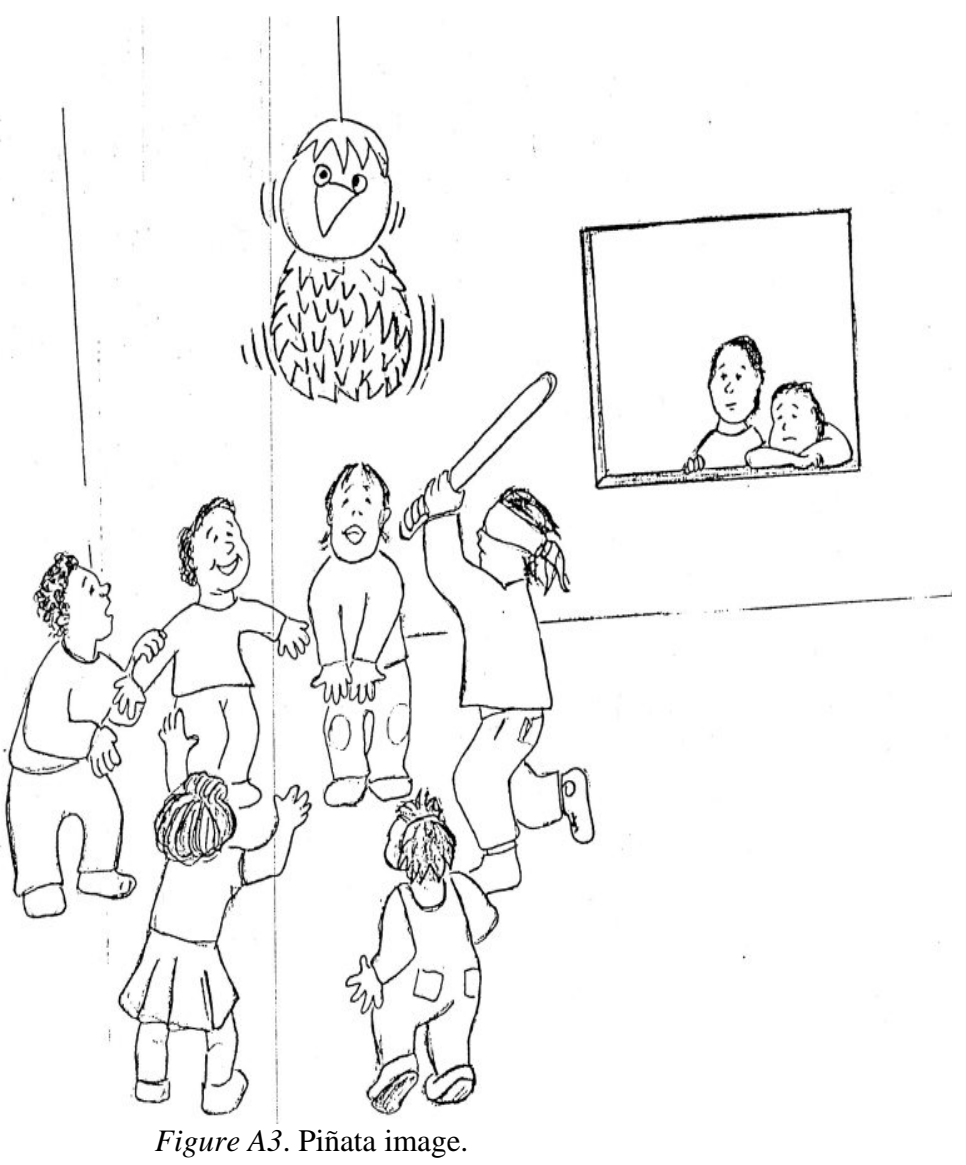




\section{Appendix B: Description of the Conglomerates and the Specific Categories}

\section{Conglomerates and Specific Categories of Moral Domain}

Concern about harm. This conglomerate groups together the justifications referred to an intention or real interest in avoiding physical or emotional harm to people involved in a given situation. Based on this kind of argumentation, children can accept exclusion, depending on whether they perceive some risk to the other participants in the activity, the intention of the agent to harm another or a risk of retaliation because of a previous situation considered by the individual as an offense or damage. The conglomerate encompasses the following specific categories:

(1) References to physical aggression: justifications in which he who causes physical harm to others is excluded;

(2) References to humiliation: argumentations in which a psychological form of harm such as mockery, indifference or scorn are posited;

(3) References to revenge: justifications referred to cases in which children exclude other children in revenge or retaliation for a prior offense.

Justice A. This conglomerate groups together justifications referred to the interest of guaranteeing equality in terms of impartial treatment in the access to goods, resources, and opportunities in the public sphere; concern for individual and collective rights; and the respect for the dignity and integrity of the other. The conglomerate encompasses the following specific categories:

(1) References to human rights: justifications referred to the need to guarantee an impartial treatment for all individuals; that is, a stand against discrimination in matters of race, gender, or socio-economic condition;

(2) References to the right to intimacy to decide whom they want to associate with: justifications by which a person claims autonomy to decide about matters that have to do with the private sphere such as choosing the people one wants to have a close relationship with or claiming the right to decide who shall belong or participate in an intimate space.

Justice B. This conglomerate groups together justifications referred to the interest to permit that all persons participate in the activity without taking into account any criterion, principle, or right. These references, permeated by the interest in preventing harm to oneself and others, are presented more like institutions of justice that the child cannot defend with arguments. The conglomerate encompasses the following specific categories:

(1) References to equality of opportunities: justifications that reflect a concern for ensuring that all persons involved in a situation have the same access to resources, opportunities, and benefits;

(2) References to egalitarianism: justifications referred to the interest of the child in guaranteeing the same things or the same opportunities for all involved, without considering relevant situational aspects such as a particular condition of need in one person, or the different capacities and different merits of persons.

Ideal self A. In this conglomerate, justifications are referred to the preservation of a self image, but are conditioned by the evaluation of others and by social expectations of what an ideally good person is like. This includes references to a definition of the self as a good person that must share, and must not be envious nor fight.

Ideal self B. This conglomerate groups together justifications reflecting a concern for the following of moral precepts linked to the preservation of a self image that constitutes a fundamental aspect of self-definition. These judgments are congruent with the characteristics of identity, and do not depend on social expectations but rather on the subjects autonomy. This includes references to a definition of the self as a person that must be consistent with his/her own principles; that is, he/she must be just, honest, trustworthy and try to guarantee the equality of human beings.

Benevolence. This conglomerate groups together justifications referred to the interest of caring for the other, bearing in mind their feelings and their particular situation. This kind of justifications reflect a position of solidarity and empathy of the subject towards a situation of need, disadvantage or suffering of the other. The conglomerate encompasses the following specific 
categories:

(1) References to welfare: justifications in which exclusion appears as a preventive measure given the possibility that a person (the excluding individual or the person who is being excluded) and/or the group may be harmed;

(2) Consideration of the other: Under this category, we include the concern of the children for giving an opportunity to other so that they may prove their good intentions or character. We also include the concern for taking others into account and tending to their needs;

(3) References to the strongest: justifications in which there is an interest in including the strongest individual in the activity, not because he is the most apt or skillful for a given goal but because he would not be harmed, or could participate in the defense of another. In the same way, the strongest individual is excluded because of the possibility that he would harm others.

\section{Conglomerates and Specific Categories of Social-conventional Domain}

Prejudice. This conglomerate groups together the reasons referred to characters in the images where these are expected to behave in a certain way because they show certain physical characteristics or belong to a certain class, group, or race. The prejudice category supposes a rejection of said character by virtue of certain physical, psychological, or cultural characteristics that are negatively evaluated. These kinds of judgments may be expressed with a moral tone, in that he upon whom the prejudice falls is considered to be a moral transgressor. They may also be expressed as judgments of a personal kind, in that the prejudices and/or stereotypes have to do with tastes, preferences, interests, or wishes of the subject. The conglomerate encompasses the following specific categories:

(1) References to gender: justifications in which differences of gender can limit access and participation in an activity for certain persons;

(2) References to race: justifications in which differences of race can limit access and participation in an activity for certain persons;

(3) References to social class: justifications referred to physical characteristics, behaviors, or customs associated with social classes, upon which a justification for exclusion is built;

(4) References to political and religious beliefs, and to sexual orientation: justifications in which there is a negative value judgment with respect to the ideological leanings or sexual orientation of the excluded subject;

(5) References to other kinds of prejudices or stereotypes: justification in which a preconceived and arbitrary judgment is observed, that has as an object a person or group, and that may be of a favorable or unfavorable nature.

Goals of the activity. This conglomerate groups together justifications referred to objectives or conditions that determine the participation of someone in an activity. Situations may be differentiated by seeing whether they have a competitive objective where playing skill is fundamental or rather have fun and amusement as a goal, or whether the situation is intimate, a close gathering of friends. In this case, the grounds for excluding a person are that said person's characteristics will hamper the accomplishment of the activity's objective, all personal or moral justifications aside. The conglomerate encompasses the following specific categories:

(1) References to skills to carry out the activity: justifications referred to the physical skills or technical knowledge necessary to develop the activity in such a way that the objective of the group is accomplished;

(2) References to knowledge of the rules of an activity: justifications in which those who do not have knowledge of the norms of the activity are excluded, because this affects their performance and that of other participants in the activity;

(3) References to goals or ends of an activity: justifications in which the accomplishment of an activity's goals are posited as a valid criterion for exclusion or inclusion. Objectives are different in each situation, but the child recognizes that objectives are above particular interests or personal preferences. 
Social convention. This conglomerate encompasses judgments referred to rules, parameters, shared beliefs, customs, social formalities, roles and functions, rituals, group identities, and regularities that have to do with social organization. The conventional is presented in different ways. In the context of informal and formal play, corresponding to images 1 and 2 , the conventional justifications are referred to rules or parameters typical of this kind of activity that determine how a game should be played. In the context of intimacy, corresponding to image 3, the conventional appear in terms of formulating patterns of relations with close groups, as well as in terms of customs, ways of dressing or norms of behavior accepted in a culture. With respect to conventional justifications, it can be pointed out that these may be expressed as references to independent actions that neither define nor characterize an activity as a whole, or as rigid patterns that must be followed obligatorily because failing to do so is considered a moral fault. They may also be expressed as parameters or conditions given by the characteristics of the activity, that do not have an obligatory character and that depend upon a consensus or agreement of the social group involved in the matter. The conglomerate encompasses the following specific categories:

(1) References to non-compliance with norms: justifications in which the subject is excluded for intentionally transgressing a norm of parameter of the situation;

(2) References to expected norms of good conduct: justifications referred to the conduct that is expected of an individual in certain situations such as not swearing, obeying a teacher or parents, speaking softly, respecting someone else's home etc.;

(3) References to social conventions: justifications referred to certain formalities, customs and accepted parameters established by a community, group, or tradition in order to participate in a specific activity (for example: a certain dress code must be followed, one must not arrive late);

(4) References to group characteristics: justifications in which group characteristics seen as a common identity, union towards a goal, or idiosyncratic characteristics are posited as reasons to validate inclusion or exclusion;

(5) References to consensus: In this category we group justifications referred to agreements, covenants and/or commitments established between the individuals or within a group, which serve as a normative criterion to establish conditions of admission and participation of a person in a given activity.

Fear of disapproval. This conglomerrate groups together justifications to exclude someone because of fear of being negatively judged or evaluated by others, or of receiving some kind of sanction. In some cases, possible reproval of adults with authority is emphasized, such as that of parents or teachers. In other cases, disapproval is presented in relation to the opinions or attitudes of the social group to which the individual belongs, or of his closest friends or companions. The conglomerate encompasses the following specific categories:

(1) References to a particular authority: justifications in which the subject delegates the decision about exclusion to someone who is an authority figure for him;

(2) References to a fear of sanction or disapproval from others: justifications in which a subject's heteronomy is visible, in which he/she decides for or against an action with the end of avoiding punishment or rejection from significant persons.

\section{Conglomerate and Specific Categories of Personal-Relational Domain}

Personal choice or preference. This conglomerate groups together reasons or justifications referred to the choices and decisions of an individual (that could be the excluding or excluded person) according to his/her tastes, interests or wishes, and the bonds or interpersonal relationships that constitute a motive for exclusion or inclusion in a given activity, without taking into account conventional or moral elements that may be part of the situation. Justifications depend on the way the subject characterizes him or herself and how he/she characterizes others, in a range that goes from consideration of physical or observable behavioral traits to the conception of intentions, motivations, feelings, thoughts and even unconscious reasons. This conglomerate encompasses the following specific categories: 
(1) References to the physical characteristics of the others: this groups together justifications in which children posit a person's physical traits as a motive for inclusion or exclusion;

(2) References to personality traits, mental components that explain a person's actions, the specific functioning of a group or the consequences that a determined situation may have for another. These aspects contemplate motivations, feelings, emotions, intentions, personality traits and other sorts of characteristics that suppose a theory on the mental functioning of others;

(3) References to feelings generated by another: justifications in which feelings, (positive or negative) that a person generates are alluded to, and are given as a personal reason to validate inclusion or exclusion of someone from a given activity;

(4) References to relations or existing bonds of friendship between people. Descriptions of friendly relations referring to activities that congregate a group of people, affinities, feelings or common history that would constitute a group of friends;

(5) References to the intention of not participating in an activity: justifications in which it is said that the child is not outside the activity because he has been excluded, but because the child himself does not wish to take part in it because of some personal motive or reason;

(6) References to personal preferences: justifications referred to tastes, interests, or personal wishes that give rise to the exclusion or inclusion of an individual from the activity. 